\title{
Proteínas de baixo peso molecular do plasma seminal bovino relacionadas com a congelabilidade do sêmen através de eletroforese bidimensional em gel de poliacrilamida*
}

\author{
Low molecular weigth proteins of bovine seminal plasma related with semen freezability using \\ two-dimensional polyacrilamide gel electrophoresis \\ Maria Inês Mascarenhas J obim ${ }^{1}$, Eneder Rosana Oberst ${ }^{1}$, Christianne Gazzana Salbego ${ }^{2}$, \\ Diogo Onofre Souza ${ }^{2}$, Vera Beatriz Wald ${ }^{3} \&$ Rodrigo Costa Mattos ${ }^{3}$
}

\begin{abstract}
RESUMO
A eletroforese bidimensional em géis de poliacrilamida representa uma técnica valiosa para separação e caracterização das proteínas e através deste método muitas proteínas do plasma seminal de várias espécies foram descritas e caracterizadas. O objetivo do presente estudo foi relacionar o perfil das proteínas de baixo peso molecular do plasma seminal bovino com a congelabilidade do sêmen. O plasma seminal de 16 reprodutores bovinos de maior e menor congelabilidade foram utilizados neste estudo. Foram encontradas 12 bandas protéicas nas amostras de plasma seminal analisadas nos géis SDS-PAGE a 15\%. Apenas 6 das 12 bandas foram detectadas em todos os ejaculados estudados, sendo que somente as bandas protéicas 3 (15-16kDa; pI 4,7-5,2), 5 (16-17kDa; pI 4,1-4,8) e 7 (10-12kDa; pI 4,8-4,9) não apresentaram variação significativa entre as amostras de plasma seminal dos reprodutores. Das proteínas analisadas neste estudo, 4 apresentaram-se quantitativamente superiores $(\mathrm{P}<0,05)$ nas amostras dos reprodutores pertencentes ao grupo de maior congelabilidade, as bandas 3 (15-16kDa; pI 4,7-5,2), 7 (11-12kDa; pI 4,1-4,8), 11 (13-14kDa; pI6,90-6,50) e 23 (18-20kDa; pI 4,8-5,2), enquanto que a banda protéica 25 (25-26kDa; pI 6,0-6,5) mostrou-se significativamente superior $(\mathrm{P}<0,05)$ nos reprodutores de menor congelabilidade do sêmen. As evidências encontradas neste experimento mostram que existem diferenças no perfil protéico dos reprodutores com maior e menor congelabilidade do sêmen, sugerindo as proteínas 3, 7, 11, 23 como possíveis marcadores da congelabilidade do sêmen e a proteína 25 como indicativo da menor congelabilidade do sêmen.
\end{abstract}

Descritores: proteínas, plasma seminal, congelabilidade, eletroforese.

\begin{abstract}
Two-dimensional gel polyacrylamide electrophoresis represents a valuable tool for the separation and characterization of proteins from complex biological samples. Many proteins from seminal plasma of various animal have been described and characterized and 2-D PAGE has been widely used for their separation and analysis. The objectives of this study were to evaluate the low weight protein profile of bovine seminal plasma using two-dimensional polyacrylamide gel electrophoresis (2D-PAGE) and to find if any of these proteins was correlated with semen freezability. A total of 16 bull seminal plasma were used in this study. Of the 12 proteins found in the research bulls, three spots, present in all samples, 3 $(15-16 \mathrm{kDa}), 5(16-17 \mathrm{kDa})$ and $7(10-12 \mathrm{kDa})$ had not a statistically significant variation among bulls, regardless the freezability group. Four proteins showed superior relative content $(\mathrm{P}<0.05)$ in seminal plasma samples collected from bulls with high semen freezability, than in the samples of the bulls of low semen freezability: the spots 3 (15-16kDa, pI 4.7-5.2), 7 (11-12kDa, pI 4.8-4.9), 11 (13-14kDa, pI 6.0-6.5) and 23 (20-22kDa, pI 4.8-5.2). On the other hand, the spot 25 (25-26kDa, pI 6.0-6.5) showed superior relative protein content $(\mathrm{P}<0.05)$ on seminal plasma samples from bulls with low semen freezability. The data found out in this study suggest protein profile differences between high and low bulls semen freezability and that the proteins 3 , 7,11 and 23 can be used as a semen freezability marker and the protein 25 would be related with low semen freezability.
\end{abstract}

Key words: proteins, seminal plasma, freezability, two-dimensional electrophoresis.

* Trabalho extraído da Tese de Doutorado do $1^{\circ}$ autor. Curso de Pós-Graduação em Medicina Veterinária, UFSM, Santa Maria, RS.

${ }^{1}$ Setor de Inseminação Artificial, Departamento de Patologia Clínica Veterinária (DPCV), Faculdade de Veterinária (FAVET), Universidade Federal do Rio Grande do Sul (UFRGS). ${ }^{2}$ Departamento de Bioquímica, Instituto de Ciências Básicas da Saúde (ICBS) - UFRGS. ${ }^{3}$ Departamento de Medicina Animal/FAVET - UFRGS. CORRESPONDÊNCIA: M. I. M. Jobim [e-mail: ines.jobim@vortex.ufrgs.br; Fax +55 51 3316 7305]. Setor de Inseminação Artificial, DPCV/ FAVET - UFRGS. Caixa Postal 15094; 91501-970 Porto Alegre, RS - Brasil. 


\section{INTRODUÇÃO}

Nas décadas de 1950 e 1960, a técnica de eletroforese começou a ser utilizada para mapear e identificar componentes protéicos solúveis de ejaculados [4, $21,43]$. Inicialmente, foi utilizada a eletroforese em soluções de sacarose [21], a qual foi substituída pelos géis de amido [46], mas os melhores resultados foram obtidos através da eletroforese em géis de poliacrilamida, sendo a técnica utilizada com sucesso até os dias de hoje.

Através de eletroforese unidimensional, o perfil protéico do plasma seminal bovino foi correlacionado com padrões de fertilidade normais [2,29] e alterados [34,49], com a congelabilidade $[37,38]$ e com a viabilidade do sêmen [1].

A eletroforese bidimensional em géis de poliacrilamida representa uma técnica valiosa para separação e caracterização das proteínas e através deste método, muitas proteínas do plasma seminal de várias espécies foram descritas e caracterizadas $[6,9,11,13$, $14,20,26]$. Analisando as proteínas de alto peso molecular no plasma seminal bovino, foram encontradas duas proteínas relacionadas à congelabilidade do sêmen [19], entretanto, o perfil das proteínas de baixo peso molecular do plasma seminal bovino ainda não foi correlacionado com a congelabilidade do sêmen através do uso de eletroforese bidimensional.

Este trabalho objetivou avaliar o perfil das proteínas de baixo peso molecular do plasma seminal de reprodutores bovinos de uma Central de Inseminação Artificial através de eletroforese bidimensional, bem como relacionar o perfil destas proteínas com a congelabilidade do sêmen de touros doadores.

\section{MATERIAIS E MÉTODOS}

Foram utilizados 16 reprodutores adultos, doadores de sêmen de uma central de inseminação artificial, pertencentes às espécies Bos taurus taurus (9) e Bos taurus indicus (7), mantidos sob o mesmo regime de manejo e alimentação e subdivididos em dois grupos, de acordo com o grau de congelabilidade do sêmen. A formação dos grupos dos reprodutores, de acordo com a congelabilidade do sêmen, foi baseada no histórico de produção da central de inseminação artificial dos últimos 2 anos. Os animais com sêmen de maior congelabilidade foram aqueles que, neste período, apresentaram mais de $90 \%$ (90 - 100\%) de seus ejaculados aproveitáveis após descongelação das palhetas de sêmen, ou seja, de acordo com os padrões recomendados pelo Colégio Brasileiro de Reprodução Animal [8], e utilizados pela central. Por outro lado, foram considerados reprodutores de menor congelabilidade do sêmen aqueles que apresentaram percentagem menor que $90 \%$ (0 - 86\%) dos ejaculados aproveitáveis pós-descongelamento. A coleta das amostras foi realizada após o grupamento dos touros de acordo com o grau de congelabilidade do sêmen.

O sêmen foi colhido através do método da vagina artificial, rotineiramente utilizado na central. Após a coleta e exame, uma alíquota de $2,0 \mathrm{~mL}$ de sêmen foi centrifugada a $1.500 \mathrm{~g}$ por 15 a 20 minutos para obtenção do plasma seminal, o qual foi acondicionado em tubos plásticos com rosca e congelado em botijão de nitrogênio líquido para posterior análise no laboratório. As amostras foram descongeladas, recentrifugadas a $10000 \mathrm{~g}$ por 60 minutos $\mathrm{a}+4^{\circ} \mathrm{C}$ e o sobrenadante foi acondicionado em frascos criogênicos em alíquotas de $50 \mu \mathrm{L}$, mantidas a $-70^{\circ} \mathrm{C}$, até sua utilização.

Para a análise das proteínas foi coletada 1 amostra de plasma seminal de cada reprodutor (agosto de 1999), sendo efetuadas, pelo menos, 2 reaplicações nos géis para eletroforese.

A determinação de proteínas totais foi realizada pelo método de Lowry et al. [23], utilizando como padrão albumina sérica bovina $(1 \mathrm{mg} / \mathrm{mL})$.

A técnica de eletroforese bidimensional foi realizada pelo método de O'Farrel et al. [31] modificado [35]. A primeira dimensão constituiu-se de focalização isoelétrica não equilibrada (NEPHGE) em gel tubular de poliacrilamida a 3,5\% [22], com gradiente de $\mathrm{pH}$ de 2 a $10 .{ }^{1}$ Foi aplicada uma quantidade de $100 \mu \mathrm{g}$ de proteína em cada tubo e foi usado como marcador de frente de corrida o citocromo C. A fonte utilizada foi EPS $3501^{1}$ com voltagem máxima de $800 \mathrm{~V}$, amperagem máxima de $10 \mathrm{~mA}$ e potência de $0,125 \mathrm{~W}$ por gel. A corrida teve a duração de 90 minutos e foi interrompida quando a banda visível de citocromo $\mathrm{C}$ atingiu $7,5 \mathrm{~cm}$ de migração. Os tubos foram então retirados da cuba, identificados e mantidos a $-20^{\circ} \mathrm{C}$, até o momento da transferência para a segunda dimensão.

Para a segunda dimensão foi utilizada eletroforese em placas de gel (SDS-PAGE), com sistema de tampão descontínuo, que separa as proteínas pelo seu peso molecular. Foram consideradas proteínas de baixo peso molecular aquelas com peso molecular igual ou inferior a $40 \mathrm{kDa}$. Foi utilizado gel de separação com uma 
concentração de $15 \%$ de acrilamida. Foi utilizado como padrão M39132, o qual marca os pesos moleculares entre 6,5 e $66 \mathrm{kDa}$, aplicando-se uma quantidade de $20 \mu \mathrm{L}$.

Os géis foram corados com solução de Comassie Brilliant Blue 250-R (Comassie Blue 0,15\%, metanol $53 \%$ e ácido acético $7 \%$ em água bi-destilada) por aproximadamente 18 horas. A descoloração dos géis para evidenciação das bandas foi efetuada em solução de metanol $50 \%$ e ácido acético $7 \%$ em água bidestilada. Por cerca de 3 horas e a seguir, os géis foram imersos numa solução de secagem (metanol $50 \%$ e glicerol $1 \%$ em água bi-destilada) por 2 horas. Os géis foram secos entre duas folhas de celofane e então escaneados ${ }^{3}$ e analisados pelo programa Optiquant Acquisition \& Analysis (versão 02.00) ${ }^{4}$ para determinação da densidade óptica das bandas protéicas, as quais foram expressas em pixeis. A densidade óptica das bandas protéicas foi expressa em percentagem relativa, sendo que $100 \%$ representa o total de bandas (pixeis) de uma área definida, constante para todos os géis, correspondendo cada banda protéica a uma percentagem do total.

Através do peso molecular e do ponto isoelétrico (pI) aproximado, foi verificada a correspondência entre as bandas protéicas analisadas e as proteínas específicas do plasma seminal bovino já descritas na literatura.

O delineamento utilizado foi completamente ao acaso com repetições (géis), sendo considerado como fator em estudo a congelabilidade (maior e menor) e como erro experimental os touros dentro da congelabilidade. Como variável resposta foram considerados os logaritmos das percentagens relativas da densidade óptica das bandas protéicas. Foi utilizada a análise de variância (ANOVA), com um nível de significância de $5 \%$. O programa estatístico utilizado foi o SAS (Statistical Analysis System) versão 6-12.

\section{RESULTADOS}

Os valores encontrados na determinação de proteína total do plasma seminal bovino foram de $76,96 \pm 18,27 \mathrm{mg} / \mathrm{mL}$ nas amostras de plasma seminal dos reprodutores de maior congelabilidade, enquanto que nas amostras dos reprodutores de menor congelabilidade foram de 79,39 $\pm 11,64 \mathrm{mg} / \mathrm{ml}$, não se encontrando diferença significativa $(\mathrm{P}=0,6878)$ entre as amostras de plasma seminal de ambos os grupos.

A distribuição das bandas protéicas de baixo peso molecular do plasma seminal bovino pode ser observada na Figura 1 e na Tabela 1. Foram encontradas 12 bandas protéicas nas amostras analisadas nos géis de $S D S-P A G E$, sendo que nenhum dos ejaculados apresentou todas as 12 bandas protéicas. As amostras de plasma seminal de 2 reprodutores apresentaram 11 bandas, as amostras de 8 reprodutores apresentaram 10 bandas, as amostras de 5 reprodutores apresentaram 9 bandas e as amostras do plasma seminal de um reprodutor apresentou 7 bandas.

Apenas 6 das 12 bandas foram constantes em todos os ejaculados, denominadas proteínas $3(15-16 \mathrm{kDa})$, 5(16-17kDa), 7 (10-12kDa), 9 (14-15kDa), 17 (15-16kDa) e $21(18-20 \mathrm{kDa})$ (Figura 1, Tabela 1). Entretanto, apenas as bandas correspondentes às proteínas 3,5 e 7 não apresentaram variação quantitativa individual entre as amostras do plasma seminal dos touros (Tabela 1, Figura 1).

Tabela 1. Freqüência, peso molecular, pl, densidade óptica média, desvio padrão,valores máximo e mínimo das proteínas de baixo peso molecular do plasma seminal de 16 reprodutores bovinos

\begin{tabular}{|c|c|c|c|c|c|c|c|}
\hline $\begin{array}{l}\text { Bandas } \\
\text { Protéicas }\end{array}$ & $\begin{array}{c}\text { Freqüência das } \\
\text { bandas nos touros }\end{array}$ & Peso Molecular kDa & pl & $\begin{array}{c}\text { Média e desvio } \\
\text { padrão }(\%)\end{array}$ & $\begin{array}{c}\text { Máximo } \\
(\%)\end{array}$ & $\begin{array}{l}\text { Mínimo } \\
(\%)\end{array}$ & $\mathbf{P}$ \\
\hline 3 & $100,00 \%(16 / 16)$ & $15-16$ & $4,7-5,2$ & $13,01 \pm 3,83$ & 22,83 & 7,26 & 0,5234 \\
\hline 5 & $100,00 \%(16 / 16)$ & $16-17$ & $4,1-4,8$ & $1,33 \pm 0,35$ & 2,52 & 0,93 & 0,2591 \\
\hline 7 & $100,00 \%(16 / 16)$ & $11-12$ & $4,8-4,9$ & $1,22 \pm 0,72$ & 3,51 & 0,78 & 0,1594 \\
\hline 9 & $100,00 \%(16 / 16)$ & $14-15$ & $5,5-6,0$ & $1,50 \pm 1,64$ & 6,68 & 0,32 & 0,0001 \\
\hline 11 & $93,75 \%(15 / 16)$ & $13-14$ & $6,0-6,5$ & $1,20 \pm 0,62$ & 2,42 & 0,00 & 0,0001 \\
\hline 13 & $31,25 \%(5 / 16)$ & $14-15$ & $6,5-7,0$ & $0,20 \pm 0,36$ & 1,03 & 0,00 & 0,0001 \\
\hline 15 & $93,75 \%(15 / 16)$ & $11-12$ & $7,5-8,0$ & $0,52 \pm 0,19$ & 0,91 & 0,00 & 0,0012 \\
\hline 17 & $100,00 \%(16 / 16)$ & $14-16$ & $8,0-8,5$ & $0,55 \pm 0,14$ & 1,14 & 0,42 & 0,0001 \\
\hline 19 & $37,50 \%(6 / 16)$ & $16-18$ & $7,0-7,5$ & $0,15 \pm 0,23$ & 0,81 & 0,00 & 0,0001 \\
\hline 21 & $100,00 \%(16 / 16)$ & $20-24$ & $7,2-7,5$ & $1,89 \pm 0,29$ & 2,61 & 1,23 & 0,0001 \\
\hline 23 & $62,50 \%(10 / 16)$ & $18-20$ & $4,8-5,2$ & $0,37 \pm 0,27$ & 0,91 & 0,00 & 0,0001 \\
\hline 25 & $56,25 \%(10 / 16)$ & $25-26$ & $6,0-6,5$ & $0,18 \pm 0,19$ & 0,91 & 0,00 & 0,0001 \\
\hline
\end{tabular}

(P) Valor da probabilidade do teste de comparação entre touros. 


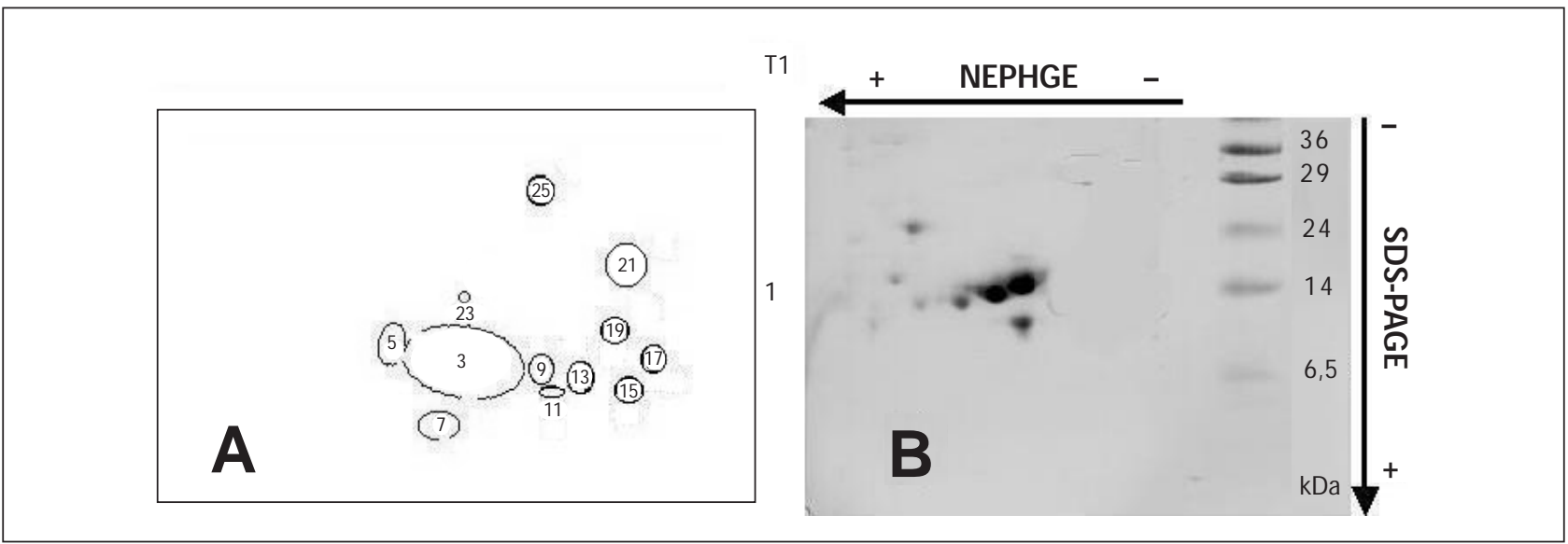

Figura 1. Perfil eletroforético das proteínas de baixo peso molecular do plasma seminal bovino. Em A: desenho esquemático das proteínas de baixo peso molecular representadas por círculos com número correspondente. A numeração designa a banda protéica descrita na tabela 1. Em B: Gel bidimensional SDS-PAGE a 15\%, corado com Comassie Blue, mostrando as proteínas de baixo peso molecular do plasma seminal bovino. A seta superior indica a direção do gradiente de pH não-equilibrado $(N E P H G E)$ na primeira dimensão. Os marcadores de peso molecular estão à direita, com os respectivos pesos.

A frequiência das bandas protéicas $11,13,15$, 19,23 e 25, que não foram constantes nas amostras de todos os reprodutores, encontra-se expressa na tabela 2. Pode-se observar que $9(90 \%)$ das amostras provenientes dos 10 touros de maior congelabilidade do sêmen apresentaram a banda protéica $23(\mathrm{P}=0,0076)$, enquanto que, das amostras provenientes dos 6 touros de menor congelabilidade do sêmen, apenas uma $(16,66 \%)$ apresentou a referida banda, havendo diferença significativa $(\mathrm{P}=0,0076)$ entre as freqüência destes dois grupos. As demais bandas protéicas não apresentaram diferença significativa quanto à freqüência entre os reprodutores de maior e menor congelabilidade do sêmen.

A densidade óptica média e desvio padrão das proteínas de baixo peso molecular [3, 7, 11, 23 e 25) do plasma seminal bovino que apresentaram diferença significativa $(\mathrm{P}<0,05)$ quando relacionadas a congelabilidade do sêmen é apresentada na Tabela 3 e Figura 2.
Das proteínas analisadas neste estudo, 5 apresentaram diferença quantitativa entre as amostras dos reprodutores pertencentes ao grupo de maior congelabilidade, daquelas provenientes dos reprodutores de menor congelabilidade do sêmen, as bandas 3 (15-16kDa, pI 4,7-5,2), 7 (11-12kDa, pI 4,8-4,9), 11 (13-14kDa, pI 6,0-6,5), $23(16-18 \mathrm{kDa}, \mathrm{pI} 4,8-5,2)$ e $25(25-26 \mathrm{kDa}, \mathrm{pI}$ 6,0-6,5) (Tabela 3, Figura 2). A proteína 23 apresentou densidade óptica significativamente superior nas amostras dos reprodutores de maior congelabilidade do sêmen, porém foi detectada em amostras de apenas um dos reprodutores considerados de menor congelabilidade. A proteína 25 , contrariamente às demais bandas protéicas (3, 7, 11 e 23) que apresentaram valores de densidade óptica superior nos reprodutores de maior congelabilidade do sêmen, apresentou valores superiores nos reprodutores de menor congelabilidade. As demais bandas protéicas $(5,9,12,15,17,19,21)$ encontradas neste estudo não apresentaram densidades ópticas com diferenças significativas quanto à congelabilidade do sêmen.

Tabela 2. Freqüência das bandas protéicas $11,13,15,19,23$ e 25 conforme a congelabilidade do sêmen.

\begin{tabular}{|c|c|c|c|c|c|c|c|}
\hline \multirow{2}{*}{ Congelabilidade } & \multirow{2}{*}{ Touros $\mathbf{n}$} & \multicolumn{6}{|c|}{ Freqüência das bandas protéicas nos reprodutores } \\
\hline & & 11 & 13 & 15 & 19 & 23 & 25 \\
\hline Maior & 10 & $\begin{array}{c}100,00 \% \\
(10 / 10)\end{array}$ & $\begin{array}{c}20,00 \% \\
(2 / 10)\end{array}$ & $\begin{array}{c}100,00 \% \\
(10 / 10)\end{array}$ & $\begin{array}{c}30,00 \% \\
(3 / 10)\end{array}$ & $\begin{array}{c}90,00 \%{ }^{a} \\
(9 / 10)\end{array}$ & $\begin{array}{c}30,00 \% \\
(3 / 10)\end{array}$ \\
\hline Menor & 6 & $\begin{array}{c}66,66 \% \\
(4 / 6)\end{array}$ & $\begin{array}{c}33,33 \% \\
(2 / 6)\end{array}$ & $\begin{array}{c}83,33 \% \\
(5 / 6)\end{array}$ & $\begin{array}{c}50,00 \% \\
(3 / 6)\end{array}$ & $\begin{array}{c}16,66 \% \\
(1 / 6)\end{array}$ & $\begin{array}{c}100,00 \% \\
(6 / 6)\end{array}$ \\
\hline
\end{tabular}


Tabela 3. Densidade óptica média e desvio padrão das proteínas de baixo peso molecular do plasma seminal bovino que apresentaram diferença quanto a congelabilidade do sêmen.

\begin{tabular}{cccccc}
\hline Congelabilidade & Proteína 3 & Proteína 7 & Proteína 11 & Proteína 23 & Proteína 25 \\
\hline Maior & $14,09^{\mathrm{a}} \pm 3,74$ & $2,33^{\mathrm{a}} \pm 0,64$ & $1,48^{\mathrm{a}} \pm 0,54$ & $0,48^{\mathrm{a}} \pm 0,21$ & $0,09^{\mathrm{a}} \pm 0,21$ \\
Menor & $1,58^{\mathrm{b}} \pm 0,58$ & $1,29^{\mathrm{b}} \pm 0,34$ & $0,65^{\mathrm{b}} \pm 0,36$ & $0,08^{\mathrm{b}} \pm 0,18$ & $0,31^{\mathrm{b}} \pm 0,15$ \\
\hline $\mathrm{a}, \mathrm{b}(\mathrm{P}<0,05)$ Letras diferentes na mesma coluna indicam diferença & significativa & &
\end{tabular}

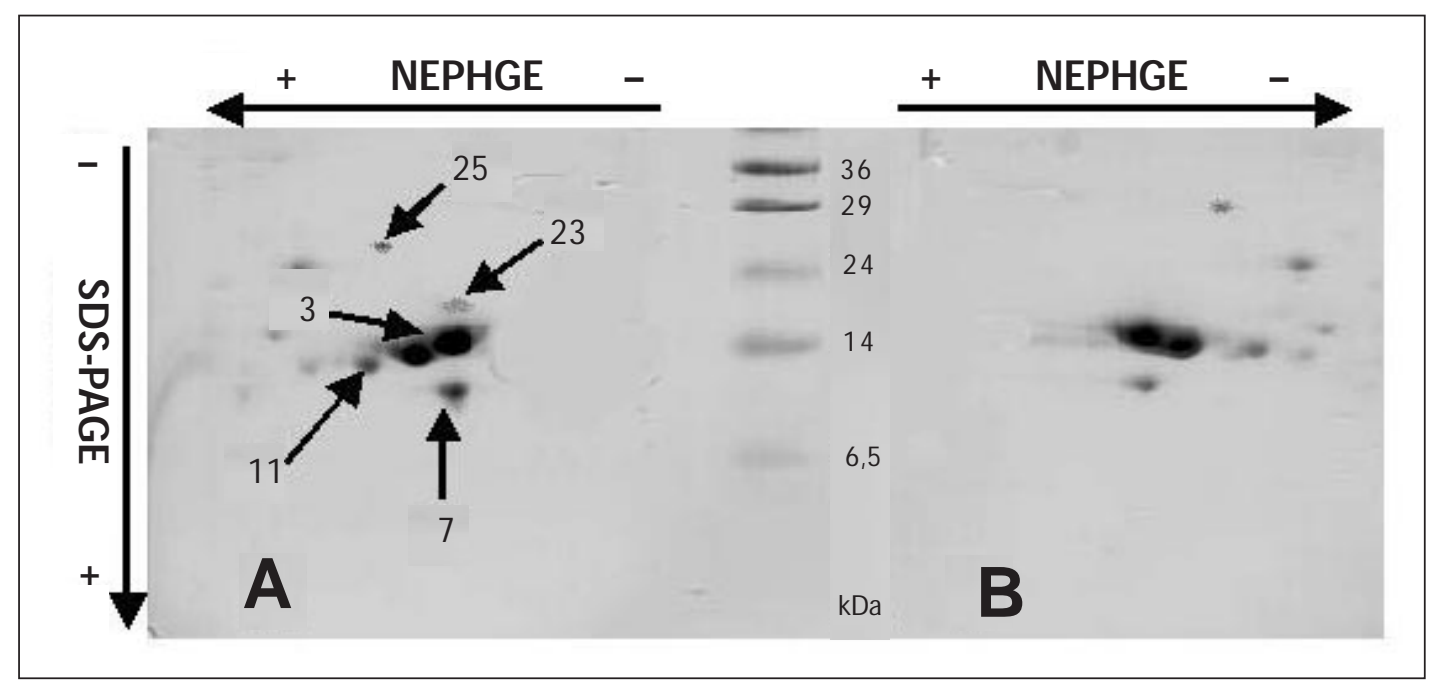

Figura 2. Proteínas de baixo peso molecular que apresentaram diferença significativa nos grupos de maior e menor congelabilidade do sêmen. Gel bidimensional SDS-PAGE a 15\%, corado com Comassie Blue. A seta superior indica a direção do gradiente de pH não-equilibrado (NEPHGE) na primeira dimensão. Os marcadores de peso molecular estão no centro e os respectivos pesos ao lado. Em A: Proteínas do plasma seminal de reprodutor de maior congelabilidade do sêmen. As setas indicam as proteínas que apresentaram diferença significativa nos grupos de alta e baixa congelabilidade do sêmen. Em B: Proteínas do plasma seminal de reprodutor de menor congelabilidade do sêmen.

\section{DISCUSSÃO}

Os valores encontrados na determinação de proteína total do plasma seminal bovino foram de $77,97 \pm 15,82 \mathrm{mg} / \mathrm{mL}$ e situam-se dentro dos valores referidos na literatura $[27,30,32]$. Ainda foi observado que, quanto maior a concentração de proteínas totais, menor a motilidade espermática pós-congelamento [27]. Entretanto, neste estudo não foi encontrada diferença significativa $(\mathrm{P}=0,6878)$ entre as amostras de plasma seminal de reprodutores de maior e menor congelabilidade do sêmen. Os dados diferem do observado por Roncoletta [36], que encontrou valores significativamente superiores na concentração de proteínas totais nas amostras dos reprodutores de alta congelabilidade do sêmen comparativamente às de baixa congelabilidade. Cabe ressaltar que o referido autor trabalhou com 4 grupos de animais (alta, boa, média e baixa congelabilidade do sêmen) e que o perí- odo de coleta das amostras foi de 6 meses, podendo ter ocorrido flutuações na concentração das proteínas totais neste período.

Foram encontradas 12 bandas protéicas de densidades ópticas variadas e peso molecular entre 11 e $26 \mathrm{kDa}$ e $\mathrm{pI} 4,1-8,5$. Apenas 6 bandas estavam presentes em todas as amostras dos reprodutores, denominadas proteínas 3 (15-16kDa), 5 (16-17kDa), 7 (10$12 \mathrm{kDa}), 9$ (14-15kDa), 17 (15-16kDa) e 21 (18-20kDa) (Tabela 1, Figura 1). Entretanto, apenas as bandas protéicas 3, 5 e 7 não apresentaram variação entre touros (Tabela 2), demonstrando, com isto uma uniformidade de expressão. A variação observada nas demais bandas protéicas indica a existência de diferenças individuais entre os perfis de cada animal.

Com base no peso molecular e $\mathrm{pI}$ aproximado, as bandas protéicas podem corresponder a proteínas específicas do plasma seminal bovino, já descritas na literatura. 
A banda protéica 3 deste estudo, de peso molecular entre 15 e $17 \mathrm{kDa}$ e $\mathrm{pI}$ entre 4,5 a 5,5, com densidade óptica significativamente superior nos reprodutores de alta congelabilidade, foi a que apresentou maior densidade óptica, expressando valores relativos médios de 13,01 $\pm 3,83$ com um máximo de 22,83 e um mínimo de 7,26; representando 59,29\% das proteínas quantificadas nos géis. Provavelmente trata-se da PDC-109, também denominada de BSP A1/ A2 (A1 16,5kDa, pI 4,7-5 e A2 16kDa, pI 4,9-5,2) [9]. Utilizando a mesma técnica, foi verificado $[9,14]$ que as proteínas mais abundantes do plasma seminal bovino foram facilmente visualizadas num pI entre 4,6 a 7,2 , com peso molecular entre 12 a $17 \mathrm{kDa}$ e também se apresentaram sob a forma de duas bandas. Foi verificado ainda que não ocorriam variações nas concentrações relativas destas proteínas entre os ejaculados de diferentes reprodutores [14], o que está de acordo com os achados deste estudo. Foi observada uma diminuição significativa (70-80\%) na concentração das proteínas BSP ligadas à membrana espermática depois da criopreservação do sêmen, o que indica a ocorrência de modificações na membrana do espermatozóide, durante a congelação, as quais podem alterar as propriedades da membrana, levando à capacitação prematura do espermatozóide após o descongelamento [30]. Desta forma, pode-se supor que a maior quantidade desta proteína no plasma seminal, como foi observado nas amostras dos reprodutores de alta congelabilidade neste estudo, poderia conferir maior preservação das propriedades da membrana espermática durante o processo da congelação do sêmen.

A proteína 5 , de peso molecular entre 15 $16 \mathrm{kDa}, \mathrm{pI} 4,1$ a 4,8 pode corresponder tanto à BSPA3 $(15 \mathrm{kDa}, \mathrm{pI} 4,8$ - 5,2) $[9,25]$ como à proteína relacionada à baixa fertilidade encontrada por Killian et al. [20] com $16 \mathrm{kDa}$ pI 4,1. A mesma dúvida foi levantada quando da identificação das principais bandas protéicas do plasma seminal bovino em géis $S D S$ $P A G E$, a $15 \%$ [14]. A BSP-A3 possui a mesma função da BSP-A1/A2 (PDC-109), acima mencionada.

A banda protéica 7 (11-12kDa, pI 4,8-4,9) é uma das mais importantes neste estudo, porque estava presente em todas as amostras de plasma seminal analisadas e com densidade óptica significativamente superior nas amostras dos reprodutores do grupo de maior congelabilidade. Provavelmente pode corresponder à proteína ácida do fluido seminal bovino aSFP $(12,9 \mathrm{kDa} . \mathrm{pI} 4,8)[10,47,7]$. Foi sugerido que a estrutura da aSFP pode ser responsável pela preservação da membrana, possuindo um efeito antioxidativo na peroxidação lipídica da membrana da célula espermática in vitro [41]. O estresse sofrido no processo da criopreservação tem como resultados a sobrevivência, o prejuízo da função e a morte da célula espermática [15]. O peróxido é produzido e liberado pelas membranas das células mortas, em detrimento dos espermatozóides vivos [39]. Conseqüentemente a presença da aSFP, quantitativamente superior nos reprodutores de maior congelabilidade do sêmen, pode ser explicada pelo poder de preservação da membrana do espermatozóide contra a peroxidação, conferido por esta proteína.

As bandas protéicas 9, 17 e 21, apesar de serem comuns a todas as amostras dos reprodutores, apresentaram diferença significativa entre os touros, indicando uma variação individual nos perfis protéicos de cada reprodutor.

A banda protéica 9 (14-15kDa, pI 5,5-6,0) pode corresponder à proteína Z13 (13kDa, pI 5,5) purificada e classificada, da mesma forma que a aSFP como uma espermadesina, mas com características estruturais distintas das descritas no suíno [45].

A banda protéica 17 (14-16kDa, pI 8,0-8,5) deve ser a ribonuclease BS 1 , uma proteína de $13,6 \mathrm{kDa}$, pI, 8,98 classificada como uma das principais proteínas básicas do plasma seminal bovino [40]. Foi demonstrado que esta proteína cobre a superfície do espermatozóide ejaculado [42]. Os bovinos são a única espécie que produzem a ribonuclease seminal [7].

A banda protéica $21(20-24 \mathrm{kDa}, \mathrm{pI} 7,2-7,5)$ representa $8,54 \%$ das proteínas quantificadas nos géis, e é provável tratar-se da proteína P6 (20kDa), classificada como uma das principais proteínas básicas do plasma seminal [40]. É secretada pelas vesículas seminais e é idêntica à MCP-1 (monocytte-chemoattractant protein-1) bovina [48], que é uma importante quimocina que recruta monócitos para os vasos sangüíneos [17].

As demais bandas protéicas 11, 13, 15, 19, 23 e 25 não foram detectadas em todas as amostras dos reprodutores e a frequiência destas bandas é mostrada na Tabela 3. 
A banda protéica 11 (13-14kDa, pI 6,0-6,5) pode corresponder às proteínas BSP A1/A2 (PDC 109) ou A3, pois foi observado que as BSP mostraram heterogeneidade de carga e são representadas por um grupo de bandas com o mesmo peso molecular, mas distribuídas em pontos isoelétricos diferentes [9]. Da mesma forma que as BSP A1/A2 (PDC 109), a proteína 11 mostrou-se superior nas amostras de plasma seminal de reprodutores de maior congelabilidade do sêmen.

A banda protéica $13(14-15 \mathrm{kDa}$, pI 6,5-7,5) provavelmente deve corresponder à EPV $20(14,6 \mathrm{kDa}, \mathrm{pI}$ 7,65 ), foi detectada no plasma seminal bovino [26], porém a função desta proteína ainda não é conhecida [28].

A banda protéica 15 (11-12kDa, pI 7,5-8,0) pode ser a Beta-2-microglobulina (11,6kDa; $\mathrm{pI} 8,24)$, encontrada e seqüenciada no plasma seminal bovino [26] é uma glicoproteína que, através de uma ligação não covalente, está ligada a uma longa cadeia polipeptídica, fazendo parte do primeiro grupo (denominado de Classe I) das moléculas do HLA (Human Leucocyte Antigen) [12].

A banda protéica 19 (16-18kDa, pI 7,0-7,5) pode corresponder à TIMP 2 (inibidor da metaloproteinase 2 do tecido bovino), é uma proteína (16 e $21 \mathrm{kDa}, \mathrm{pI} 6,93$ ) que no plasma seminal, foi primeiramente identificada por Calvete et al. [7] e, posteriormente por Mortarino et al. [26]. A proteína de ligação à heparina HBP-24 observada e relacionada à fertilidade de reprodutores [3], posteriormente, quando seqüenciada apresentou $90 \%$ de identidade com a TIMP-2 [24]. Estes autores foram os primeiros a observarem a ligação da TIMP-2 ao espermatozóide.

A banda protéica 23 (18-20kDa, pI 4,8-5,2), apesar de representar apenas $1,67 \%$ das proteínas quantificadas nos géis, é outra proteína de grande interesse neste estudo. Avaliando-a sob o ponto de vista dos valores da densidade óptica, ela apresentou-se superior nas amostras dos reprodutores de maior congelabilidade. Nas amostras dos 6 reprodutores considerados de menor congelabilidade, a referida banda está ausente em 5 animais. Nas amostras do reprodutor de menor congelabilidade na qual ela foi detectada, os valores da densidade óptica foram de 0,42 , 0,48 e 0,49 , valores estes que se assemelham aos resultados apresentados pelas amostras dos reprodutores de maior congelabilidade. Por outro lado, no que se refere à freqüência desta proteína, observa-se que ela esteve presente em $90 \%$ dos reprodutores de maior congelabilidade e em apenas um reprodutor $(16,66 \%)$ do grupo considerado de menor congelabilidade do sêmen. Esta proteína pode corresponder à clusterina cadeia alfa, que foi uma das proteínas seqüenciadas do plasma seminal bovino [26], apresentando um peso molecular de $25,35 \mathrm{kDa}$ e pI de 5,54 . A clusterina é uma glicoproteína que, no homem, possui sítios de ligação à heparina [33] e pode regular o transporte e a redistribuição de lipídeos no plasma sangüíneo humano [18]. Está presente no plasma seminal, bem como na superfície da membrana da célula espermática do bovino e do homem [16]. A clusterina está envolvida em vários processos fisiológicos, incluindo adesão e agregação celular [5] e maturação espermática [44]. Tendo em vista sua localização na membrana espermática e seu papel no transporte e redistribuição de lipídeos, esta proteína poderia apresentar funções biológicas semelhantes às mencionadas para as BSP na proteção da função da membrana espermática no processo da criopreservação do sêmen.

Pelo peso molecular e pI encontrados, a banda protéica $25(25-26 \mathrm{kDa}, \mathrm{pI} 6,0-6,5)$ pode corresponder à prostaglandina $\mathrm{D}$ sintetase tipo lipocalina, uma proteína de $26 \mathrm{kDa}$, pI 6,2 relacionada à alta fertilidade de reprodutores bovinos [20] e à congelabilidade do sêmen [38]. Entretanto, os resultados deste trabalho discordam dos achados de Roncoletta et al. [38], que através de eletroforese unidimensional, encontraram $40 \%$ a mais desta proteína em reprodutores com melhor congelabilidade, tendo atribuído este efeito à capacidade da PGDS em participar de modificações de permeabilidade da membrana celular. Neste estudo, as amostras de plasma seminal dos reprodutores de menor congelabilidade apresentaram a banda correspondente à esta proteína com densidade óptica significativamente superior $(\mathrm{P}<0,05)$ às amostras dos reprodutores de maior congelabilidade, estando esta proteína presente em 100\% (6/6) das amostras dos reprodutores de menor congelabilidade e somente em 30\% (3/10) das amostras do plasma seminal de reprodutores considerados de maior congelabilidade do sêmen. $\mathrm{O}$ resultado encontrado por Roncoletta et al. [38] talvez possa ser atribuído à técnica da eletroforese unidimensional, pois em um mesmo peso molecular podem ser encontradas proteínas com pontos isoelétricos diferentes.

As evidências encontradas neste estudo indicam que existem diferenças no perfil protéico do plasma seminal dos reprodutores de maior e menor conge- 
labilidade do sêmen, sugerindo as proteínas 3 (1516kDa, pI 4,7-5,2), 7 (11-12kDa, pI 4,8-4,9), 11 (13$14 \mathrm{kDa}, \mathrm{pI} 6,0-6,5)$ e 23 (18-20kDa, pI 4,8-5,2) como possíveis marcadores da congelabilidade do sêmen e a proteína $25(25-26 \mathrm{kDa}, \mathrm{pI} 6,0-6,5)$ como indicativo da menor congelabilidade do sêmen.

A confirmação da identidade sugerida para as proteínas caracterizadas nesta pesquisa deve ser confirmada ou pelo sequienciamento, ou pelo uso de anticorpo específico, se disponível.

Entretanto, são necessários novos estudos, envolvendo um maior número de animais e mesmo, mais ejaculados do mesmo animal para que estas conclusões sejam consideradas definitivas.

\section{AGRADECIMENTOS}

Os autores agradecem a FAPERGS e Lagoa da Serra/Hollands Genetics pelo financiamento do projeto; a Lagoa da Serra/Hollands Genetics pelo material concernente aos reprodutores, bem como a Lúcia Helena Rodrigues e Carlos Silva, desta empresa, pela valiosa colaboração.

\section{NOTAS INFORMATIVAS}

${ }^{1}$ Amersham Pharmacia

${ }^{2}$ Sigma Chemical CO.- St. Louis, MO, USA

${ }^{3}$ Hewlet-Packard Scanjet $6100 \mathrm{C}$

${ }^{4}$ Packard Instrument

\section{REFERÊNCIAS}

1 Aurich J.E., Kühne A., Hoppe H. \& Aurich C. 1996. Seminal plasma affects membrane integrity and motility of equine spermatozoa after cryopreservation. Theriogenology. 46: 791-7.

2 Ax R.L., Dickson K. \& Lenz W. 1985. Induction of acrosome reactions by chondroitin sulfates in vitro corresponds to non return rates of dairy bulls. Journal of Dairy. Science. 68: 387-390.

3 Bellin M.E., Hawkins H.E., Oyarzo J.N., Vanderboom R. J. \& Ax R. 1996. Monoclonal antibody detection of heparinbinding proteins on sperm corresponds to increased fertility of bulls. Journal of Animal Science.74: 173-182.

4 Bennet J.P. 1964. Microeletrophoresis of bull, ram, boar \& rabbit seminal plasma proteins. In: Atti del V $V^{o}$ Congresso Internazionale per la Riproduzione Animale e la Fecondazione Artificiale (Trento, Itália). pp.186-189.

5 Blaschuk O., Burdzy K. \& Fritz I.B. 1983. Purification and characterization of a cell-aggregating factor (clusterin), the major glycoprotein in ram rete testis fluid. Journal Biologycal Chemical. 258: 7714-7720.

6 Brandon C.I., Heusner G.L., Caudle A.B. \& Fayer-Hosken R.A. 1999. Two-dimensional polyacrylamide gel electrophoresis of equine seminal plasma proteins and their correlation with fertility. Theriogenology. 52: 863-873.

7 Calvete J., Varela P., Sanz L., Romero A., Mann K. \& Topfer-Petersen E. 1996. A procedure for large-scale isolation of major bovine seminal plasma proteins. Protein Expression and Purification. 8: 48-56.

8 Colégio Brasileiro de Reprodução Animal. 1998. Manual para exame andrológico e avaliação do sêmen animal. 2.ed. Belo Horizonte: CBRA, 49p.

9 Desnoyers L., Thérien I. \& Manjunath P. 1994. Characterization of the major proteins of bovine seminal fluid by twodimensional polyacrylamide gel electrophoresis. Molecular Reproduction and Development. 37: 425-435.

10 Einspanier R., Einspanier A., Wempe F. \& Scheit K.H. 1991. Characterization of a new bioactive protein from bovine seminal fluid. Biochemical and Biophysical Research Communications 179: 1006-1010.

11 Flowers W.L. 1998. Boar fertility and artificial insemination. In: Proceedings of the 15th IPVS CONGRESS (Birmingham, U.K.). pp. 45-52.

12 Fraga R.S. \& Neumann J. 1996. O complexo principal da histocompatibilidade. In: Scrofernecker, M.L. Notas de Imunologia. Porto Alegre: Editora da Universidade, pp. 107-109.

13 Frazer G.S. \& Bucci D.M. 1996. Charactrization of the major polypeptides of equine seminal plasma by two-dimensional polyacrylamide gel electrophoresis. Theriogenology. 46: 1389-1402.

14 Frazer G.S., Bucci D.M. \& Brooks C.L. 1996. Two-dimensional polyacrylamide gel electrophoresis of bovine semen after cryopreservation in half-milliliter straws. Theriogenology. 46: 1103-1115.

15 Holt W.V. 2000. Basic aspects of frozen storage of semen. Animal Reproduction Science. 62: 3-22.

16 Howes E.A., Hurst S., Laslop A. \& Jones R. 1998. Cellular distribution and molecular heterogeneity of MAC393 antigen (clusterin, beta chain) on the surface membrane of bull spermatozoa. Molecular Human Reproduction. 4: 673-681. 
17 Ichiki T., Funakoshi Y., Ito K. \& Takeshit, A. 2000. Expression of monocyte chemoattractant protein-1 by nonenzymatically glycated albumin (Amadori adducts) in vascular smooth muscle cells. Biochemical and Biophysical Research Communications. 269: 666-670.

18 Jenne D.E., Lowin B., Peitsch M.C., Bottcher A., Schimitz G.\& Tschopp J. 1991. Clusterin (complement lysis inhibitor) forms a high density lipoprotein complex with a polipoprotein A-1 in human plasma. Journal of Biological Chemistry. 266: 11030-11036.

19 Jobim M.I.M. 2001. Perfil eletroforético das proteínas do plasma seminal e sua relação com a congelabilidade do sêmen bovino. 156 f. Santa Maria, RS. Tese (Doutorado em Medicina Veterinária) - Curso de Pós-Graduação em Medicina Veterinária, Universidade Federal de Santa Maria.

20 Killian G.J., Chapman D.A. \& Rogowski L.A. 1993. Fertility-associated proteins in Holstein bull seminal plasma. Biology of Reproduction. 49: 1202-1207.

21 Larson B.L.7\& Salisbury G.W. 1954. The proteins of bovine seminal plasma I. Preliminary and electrophoretics studies. Journal of Biological Chemistry. 206: 741-749.

22 Lenz G., Manozzo L., Gottardo S., Achaval M., Salbego C. \& Rodnight R. 1997. Temporal profiles of the in vitro phosphorylation rate and immunocontent of Glial Fibrillary Acidic Protein (GFAP) after kainic acid induced lesions in area $\mathrm{CA}_{1}$ of the rat hippocampus: demonstration of a novel phosphoprotein associated with gliosis. Brain Research. 764: 188-196.

23 Lowry O.H., Rosebrough W.J., Farr A.L. \& Randall R.J. 1951. Protein measurement with Folin phenol reagent. Journal of Biological Chemistry. 193: 265-275.

24 McCauley T.C., Zhang H.M., Bellin M.E. \& Ax R.L. 2001. Identification of a heparin binding protein in bovine seminal fluid as tissue inhibitor of metalloproteinases-2. Molecular and Reproduction Development. 58: 336-341.

25 Manjunath P. \& Sairam M.R. 1987. Purification and biochimical characterization of three major acid proteins (BSP-A1, BSP-A2 and BSP-A3) from bovine seminal plasma. Biochemical Journal. 3: 685-692.

26 Mortarino M., Tedeschi G., Negri A, Ceciliani F., Gottardi L., Maffeo G. \& Ronchi S. 1998. Two-dimensional polyacrylamide gel electrophoresis map of bull seminal plasma proteins. Electrophoresis. 19: 797-801.

27 Moustafa A. R. \& Mézáros I. 1980. Interrelationship between the total protein content of bovine seminal plasma and behaviour of the spermatozoa after freezing-and-thawing. Acta Veterinariae. Academiae. Scientiarum. Hungaricae. 28: 403-408.

28 Nakamura Y., Noriyasu N., Minamatani T., Ikuta T., Ariga H. \& Matsumoto K. 2000. Primary structure, genomic organization and expression of the major secretory protein of murine epididymis, ME 1. Gene. 251: 55-62.

29 Nass S.J., Miller D.J., Winer M.A. \& Ax R.L. 1990. Male accessory Sex glands produce heparin-binding proteins that bind to cauda epididymal spermatozoa and are testosterone dependent. Molecular and Reproduction Development. 25: 237-246.

30 Nauc V. \& Manjunath P. 2000. Radioimmunoassay for bull seminal plasma proteins (BSP-A1/A2, BSP-A3, and BSP-30 kilodaltons), and their quantification in seminal plasma and sperm. Biology of Reproduction. 63: 1058-1066.

31 O'Farrel P.Z., Goodman H.M. \& O'Farrel P.H. 1977. High resolution of two-dimensional electrophoresis of basic as well as acidic proteins. Cell. 12: 1133-1142.

32 Pangawakar G.R., Sharma R.D. \& Singh R. 1988. Protein, sialic acid and zinc concentrationin the seminal plasma of bulls in relation to freeability of semen. Indian Veterinary Journal. 65: 58-60.

33 Pankhurst J.G., Bennet C.A. \& Easterbrook-Smith S.B. 1998. Characterization of the heparin-binding properties of humen clusterin. Biochemistry. 7: 4823-4830.

34 Rocha M.C., Garcia O.S., Ferreira Neto J.M. \& Schons J.A.B. 1974. Proteína total e seu fracionamento eletroforético em plasma seminal de touros zebus com alterações reprodutivas. Arquivos da Escola Veterinária UFMG. 26: 223-233.

35 Rodnight R., Zamani R. \& Tweedale A. 1988. An investigation of experimental conditions for studying phosphorylation in micro-slices of rat brain by two-dimensional electrophoresis. Journal of Neuroscience Methods. 24: 27-38.

36 Roncoletta M. 1999. Perfil em SDS-PAGE das proteínas do plasma seminal bovino relacionados com a congelabilidade do sêmen de touros. 109 f. Jaboticabal, SP. Dissertação (Mestrado em Ciências Agrária e Veterinárias) - Faculdade de Ciências Agrárias e Veterinárias, Universidade Estadual Paulista. 
Jobim M.I.M., Oberst E.R., Salbego C.G., Souza D.O., Wald V.B. \& Mattos R.C. 2003. Proteínas de baixo peso molecular do plasma seminal bovino relacionadas com a congelabilidade do sêmen através de... Acta Scientiae Veterinariae. 31: 21-30.

37 Roncoletta M., Franceschini P.H., Lima V.F.M.H. De, Rodrigues L. H., Oliveira M.A. \& Silva C. Da. 1997. Perfil em SDSPAGE das proteínas do plasma seminal e sua relação com a congelabilidade do sêmen de touros zebuínos. Ars Veterinaria. 13: $135-140$.

38 Roncoletta M., Morani E.S.C, Franceschini P.H. \& Ramos P.R.R. 2000. Caracterização da proteína 26kDa do plasma seminal e sua relação com a congelabilidade do sêmen de touros. Arquivos da Faculdade de Veterinária UFRGS. 28 (Supl): 323.

39 Shannon P. 1978. Factors affecting semen preservation and conception rates in cattle. Journal Reproduction and Fertility. 54: 519-527.

40 Scheit K.H. 1986. The major basic protein of bull seminal vesicle secretion. Biological Chemistry Hoppe Seyler. 3: 229233.

41 Schöneck C., Braun J. \& Einspanier R. 1996. Sperm viability is influenced in vitro by the bovine seminal protein a SFP: effects on motility, mitochondrial activity and lipid peroxidation. Theriogenology. 45: 633-642.

42 Shivaji S., Rukmini V., Gupta P.D. \& Bhargava P.M. 1989. Localization of bovine seminal plasma RNA-A BS1, on the surface of bovine spermatozoa. Cell and Molecular Biology. 3: 285-291.

43 Szumowsky P. 1956. Quelques resultats de l'examen electrophoretique des proteines du plasma seminal de taureau. In: Proceedings of the 3rd International Congress on Animal Reproduction (Cambridge, U.K.). pp.102-105.

44 Sylvester C., Morales R., Oko R. \& Griswold M.D. 1991. Localization of sulfated glycoprotein-2 (clusterin) on spermatozoa and in the reproductive tract of the male rat. Biology of Reproduction. 45: 195-207.

45 Tedeschi G., Oungre E, Mortarino M., Negri A. \& Ronchi S. 2000. Purification and primary structure of a new bovine spermadhesin. European Journal of Biochemistry. 20: 6175-6179.

46 Vesselinovitch S.D. 1959. Electrophoresis of bovine semen. Part. III. Characterization of the seminal plasma proteins. Canadian Journal of Comparative Medicine. 23: 10-20.

47 Wempe F., Einspanier R. \& Scheit K.H. 1992. Characterization by cDNA cloning of the mRNA of a new growth factor from bovine seminal plasma: acidic seminal protein. Biochemical and Biophysical Research Communications. 183: 232237.

48 Wempe F., Henschen A. \& Scheit K.H. 1991. Gene expression and cDNA cloning identified a major basic protein constituent of bovine seminal plasma as bovine monocyte-chemoattractant protein-1 (MCP-1). DNA Cell Biology. 10: 671-679.

49 Wolfe D.F., Bradley J.T. \& Riddel M.G. 1993. Characterization of seminal plasma proteins and sperm proteins in ejaculates from normospermic bulls and bulls whith thermally-induced testicular degeneration. Theriogenology. 40: 1083-1091. 